\title{
Viewpoint
}

\section{Health: an essential component of national resilience}

\author{
Royi Barnea', Yossi Weiss ${ }^{1}$, Joshua Shemer ${ }^{1}$ \\ ${ }^{1}$ Assuta Medical Center, Ramat HaHayal, Tel Aviv, Israel \\ Keywords: health system, national resilience \\ https://doi.org/10.29392/001c.14134
}

\section{Journal of Global Health Reports}

Vol. 4, 2020

The term "resilience" refers to concepts of adaptation and adjustment following an adversity, disturbance or stress. ${ }^{1}$ It is used in several fields, including physics, ecology, health and social sciences, with each field having its own definition of resilience. 1,2

In the last 30 years, there has been a growing interest in the determinants of resilience and in understanding how society and individuals develop resilience. In this context, resilience has been studied at various levels: individuals, families, organizations, societies, and cultures. ${ }^{3}$ At each of these levels "resilience" is defined differently and comprises dissimilar elements. ${ }^{3}$ Moreover, the relationship between levels and their mutual influence on resilience has not been studied. ${ }^{4}$ Nonetheless, it is thought that all levels of resilience contribute to wellbeing, the ability to adapt to various situations and to cope with the aftermath of traumatic events. ${ }^{4}$

\section{NATIONAL RESILIENCE}

The term "national resilience" originally referred only to a country's military capacity, but was later expanded to include political-psychological aspects. ${ }^{5}$ According to Friedland, "national resilience" is the ability of a society to withstand adversities and crises, such as natural disasters or national security events (wars or terror attacks) in diverse realms by implementing changes and adaptations without harming society's core values and institutions. ${ }^{6,7}$ Kimhi and Eshel have suggested that community resilience and national resilience are overlapping expressions of public resilience that provides its members with social identity, a sense of belonging and security. ${ }^{5}$

Since the beginning of the second millennium, there has been a growth in the number of policy documents relating to national resilience published by various organizations and countries (Table 1). These definitions imply that national resilience is usually perceived in terms of well-being and sustainability as well as in terms of risk management which has grown from the need of countries to deal with security threats such as terrorism, economic crises (e.g. the 2008 global economic crisis), and more prevalent natural disasters due to climate change.

In 2011, the OECD started a program to measure wellbeing in various countries. Well-being measures include household, income, employment, community, education, environment, civic obligations, health, satisfaction and life, security and life-work balance. In addition to measuring well-being, the OECD has published an agenda for the ad- vancement of sustainability in the various countries - the '2030 Agenda for Changing the World'.

Evaluation of national policies for strength, well-being and sustainability of the 38 OECD countries as well as India and China has shown that determinants of resilience included first and foremost health (100\% of countries), the economy (in $88 \%$ of countries), the environment (68\%, including, agriculture, forestry, fishing, and conservation of natural resources), personal security (64\%), quality of employment (64\%), industry, infrastructure and accommodation (52\%), civil and government involvement (52\%), information, communication and innovation (48\%), education and skills (44\%), energy (40\%), transportation and logistics (24\%), plans for land utilization (12\%) and leisure, culture and community (12\%).

In Israel, following the financial crisis of 2008, a government resolution was put forth to develop indicators and metrics of well-being, sustainability and national resilience that would complement the national accounting system and the gross domestic product.

A team of professionals from the Central Bureau of Statistics, the Prime Minister's Office, the National Economic Council and the Ministry for Environmental Protection established a list of 72 quality-of-life metrics in nine areas: income and capital, civil involvement and government, employment and balance of work and leisure, education and skills, environment, health, personal and social welfare, personal security, and infrastructure and housing. ${ }^{12}$ The metrics are published annually by the government statistician in order to help and formulate up-to-date policies.

\section{HEALTH AS A DETERMINANT OF NATIONAL RESILIENCE}

A health component is included in all three levels of resilience suggesting that health is an important determinant of resilience at all societal levels. Bonanno et al. defined "personal resilience" as the ability of the individual to function in a stable manner after traumatic events and to maintain healthy functioning over time. ${ }^{12}$ Community resilience requires the community's constant and evolving ability to respond to its vulnerability and develop capabilities that help the community (1) prevent, meet and reduce the stress of a health incident; (2) to recover in a manner that will restore the community to a state of independence and at least the same level of health and social functioning after a health incident; (3) using knowledge from past experience to strengthen the community's ability to withstand the next 
Table 1: Definitions of national resilience by various organizations and countries

\begin{tabular}{|c|c|}
\hline Organization & Resilience definition \\
\hline $\begin{array}{l}\text { The Organization for } \\
\text { Economic Co-operation and } \\
\text { Development (OECD) }\end{array}$ & $\begin{array}{l}\text { - The ability of households, communities and nations to absorb and recover from shocks, whilst posi- } \\
\text { tively adapting and transforming their structures and means for living in the face of long-term } \\
\text { stresses, change and uncertainty. } \\
\text { - }{ }^{8} \\
\text { Resilience is about addressing the root causes of crises while strengthening the capacities and re- } \\
\text { sources of a system in order to cope with risks, stresses and shocks. }^{8}\end{array}$ \\
\hline $\begin{array}{l}\text { UK Department for } \\
\text { International Development } \\
\text { (DFID) }\end{array}$ & $\begin{array}{l}\text { The ability of countries, communities and households to manage change by maintaining or } \\
\text { transforming living standards in the face of shocks or stresses without compromising their long } \\
\text { term prospects. }\end{array}$ \\
\hline $\begin{array}{l}\text { The United States Agency for } \\
\text { International Development } \\
\text { (USAID) }\end{array}$ & $\begin{array}{l}\text { The ability of people, households, communities, countries, and systems to mitigate, adapt to, and } \\
\text { recover from shocks and stresses in a manner that reduces chronic vulnerability and facilitates } \\
\text { inclusive growth. }{ }^{10}\end{array}$ \\
\hline $\begin{array}{l}\text { National Security Strategy } \\
\text { doctrine, USA }\end{array}$ & $\begin{array}{l}\text { the ability to withstand and recover rapidly from deliberate attacks, accidents, natural disasters, } \\
\text { as well as unconventional stresses, shocks and threats to the economy and democratic system. }\end{array}$ \\
\hline Australia & A safeguard of sovereignty while safeguarding assets, infrastructure, and institutions. \\
\hline Canada & $\begin{array}{l}\text { The ability of a system, community, or society to adapt to disturbances resulting from risks and } \\
\text { perseverance, recovery or change to achieve and maintain an acceptable level of functioning. }\end{array}$ \\
\hline
\end{tabular}

health incident. ${ }^{1,13}$ Thus, community resilience includes the protection of human life, health, economy and preparedness of infrastructures and the environment for coping. There are those who argue that community resilience is also related to perceived social support, to the strength of social connections, and to the physical and mental health of the public. ${ }^{1}$ According to Wulff et al., community resilience stems from good health and strong health systems, improved health status of populations, and the ability to maintain a healthy physical and mental state of individuals and communities and to deal with major physical and mental changes. ${ }^{14}$ Consequently, health systems can be regarded as the key to promoting community health resilience. In line with this premise, the WHO contends that the main factor that helps to create strength and resilience is a strong health system that provides a comprehensive response to all citizens. Health resilience is established by improved health status, strong health systems, good health outcomes, and is measured in the ability to preserve the physical, mental and social condition of the community and detail it in the course of large-scale changes. ${ }^{15}$ The WHO has identified six building blocks to strengthen health systems and increase resilience by improving health outcomes and accessibility as well as the health needs of the population, managing the individual's economic and social risks, and improving the efficiency of the system. These building blocks relate to public and private resources and include health services, personnel, information, access to medical equipment, vaccines and the quality and safety of technology, finance and coverage, governance and leadership. ${ }^{15}$ Strengthening the health system by improving health outcomes, such as health indicators, response to health needs, protection from economic and social risks (insurance coverage) and efficiency of the system should increase the strength and resilience of the community and the nation.

To the best of our knowledge, to date there have been no studies that evaluated health as a component of national resilience. The outcome of the Covid-19 pandemic in countries around the world will provide excellent examples for evaluating the part played by healthcare systems in national resilience.

\section{Funding: None}

Authorship contributions: All authors contributed and approved final draft of the manuscript.

Competing interests: The authors completed the Unified Competing Interest form at www.icmje.org/coi_disclosure.pdf (available upon request from the corresponding author), and declare no conflicts of interest.

\section{Correspondence to: \\ Royi Barnea \\ Assuta Medical Center \\ Ramat HaHayal \\ Tel Aviv, Israel \\ royib@assuta.co.il}


This is an open-access article distributed under the terms of the Creative Commons Attribution 4.0 International License (CCBY-4.0). View this license's legal deed at http://creativecommons.org/licenses/by/4.0 and legal code at http://creativecommons.org/licenses/by/4.0/legalcode for more information. 


\section{REFERENCES}

1. Norris FH, Stevens SP, Pfefferbaum B, et al. Community resilience as a metaphor, theory, set of capacities, and strategy for disaster readiness. Am J Community Psychol. 2008;41:127-150.

2. Myers-Smith IH, Trefry SA, Swarbrick VJ. Resilience: Easy to use but hard to define. Ideas in Ecology and Evolution. 2012;5:44-53.

3. Southwick SM, Bonanno GA, Masten AS, et al. Resilience definitions, theory, and challenges: Interdisciplinary perspectives. European Journal of Traumatic Psychology. 2014;5.

4. Kimhi S. Levels of resilience: Associations among individual, community, and national resilience. $J$ Health Psychol. 2016;21:164-170.

5. Kimhi S, Eshel Y. Individual and Public Resilience and Coping with Long Term Outcomes of War. Journal of Applied Behavioral Research. 2009;14:70-89.

6. Friedland N. The "Elusive" Concept of Social Resilience. In: Friedland N, Arian A, Kirshnbaum A, eds. The Concept of Social Resilience. Haifa: The Technion: Samuel Neaman Institute; 2005:7-10.

7. Amit K, Fleischer N, et al. Between resilience and social capital. In: Friedland N, Arian A, Kirschnbaum A, eds. The Concept of Social Resilience. Samuel Neaman Institute; 2005:83.
8. OECD. Risk and Resilience. http://www.oecd.org/de velopment/conflict-fragility-resilience/risk-resilienc e/. Accessed April 13, 2019.

9. DFID. What Is Resilience?; 2016.

10. USAID. Resilience.; 2018. https://www.usaid.gov/e ast-africa-regional/resilience. Accessed April 13, 2019.

11. National Security Strategy of the United States of America. Washington DC: The White House; 2017.

12. The State of Israel. Quality of Life Indices, Sustainability and National Resilience.; 2016.

13. Chandra A, Acosta J, Meredith L, et al. Understanding Community Resilience in the Context of National Health Security: A Literature Review. Santa Monica, CA: RAND Corporation; 2010. doi:10.7 $\underline{249 / \text { wr737 }}$

14. Wulff K, Donato D, Lurie N. What is health resilience and how can we build it? Annu Rev Public Health. 2015;36:361-374.

15. World Health Organization. Everybody's Business: Strengthening Health Systems to Improve Health Outcomes: WHO's Framework for Action. Geneva: World Health Organization; 2007. 